\title{
Local anaesthetic techniques and pulsatile ocular blood flow
}

\author{
Bernard Y P Chang, Wendy C Lum Hee, Roland Ling, David C Broadway, Bijan Beigi
}

\begin{abstract}
Aim-To compare pulsatile ocular blood flow (POBF) and intraocular pressure (IOP) between eyes of patients receiving either peribulbar (with and without balloon compression) or subconjunctival local anaesthesia (LA).

Methods-30 eyes of 30 patients undergoing cataract surgery by phacoemulsification were investigated in a study of parallel group design. Ten patients had peribulbar LA and 10 minutes compression with a Honan's balloon (group A). A further 10 patients who received peribulbar LA alone (group B) acted as controls for the effects of balloon compression. Ten other patients were given subconjunctival LA (group C). POBF and IOP were measured using a modified Langham pneumatonometer. Three measurements were made in each eye, the first recording immediately before LA, the second 1 minute after, and the third 10 minutes after LA.

Results-No significant change in POBF or IOP was recorded in eyes receiving subconjunctival LA. In the peribulbar groups ( $A$ and $B$ ), there was a drop in median POBF of 252 and $138 \mu 1 / \mathrm{min}$ respectively 1 minute after $L A$, which was statistically significant in both groups $(p<0.01)$. By 10 minutes, POBF tended to return to baseline levels, but remained significantly reduced in group $B(p<0.05)$. In addition, there was a significant $(p<0.05)$ reduction in IOP (mean drop of $4.82 \mathrm{~mm} \mathrm{Hg}$ ) in group $A$ following peribulbar LA with balloon compression. Conclusions-POBF was significantly reduced after peribulbar LA but was unchanged after subconjunctival LA. Balloon compression reduced IOP and improved POBF following peribulbar LA. The findings may have clinical implications in patients with compromised ocular circulation or significant glaucomatous optic neuropathy.

(Br f Ophthalmol 2000;84:1260-1263)
\end{abstract}

Department of

Ophthalmology,

Norfolk and Norwich

Healthcare NHS Trust,

Norwich, UK

D C Broadway

B Beigi

Correspondence to:

Mr B Beigi, Department of

Ophthalmology, West

Norwich Hospital,

Bowthorpe Road, Norwich

NR 2 3TU, UK

Accepted for publication 18 May 2000

popularity of day case surgery has increased use of local anaesthesia for intraocular surgical procedures. Peribulbar and retrobulbar injections are commonly employed anaesthetic techniques. However, less invasive techniques such as sub-Tenon's, subconjunctival, and topical anaesthesia are gaining popularity.

It has been shown that both peribulbar and retrobulbar anaesthesia can cause an increase in IOP. The increase in IOP can be reversed if compression is applied to the eye after injection ${ }^{12}$ and it is for this reason that the use of a Honan's balloon or another compression device is advocated by some surgeons.

The effect of different types of local anaesthetic procedure on ocular blood flow, however, is not clear. High IOP and low ocular blood flow may be hazardous to eyes, especially those with compromised ocular and optic nerve head circulation such as in glaucoma or ischaemic optic neuropathy.

The advent of pneumatonography has allowed calculation of the pulsatile component of ocular blood flow $^{3}$ which includes both the choroidal and optic nerve head circulation. ${ }^{4}$

The aim of this study was to examine the effect of peribulbar local anaesthesia (with and without Honan's balloon compression) on pulsatile ocular blood flow and intraocular pressure and to compare it with the less invasive subconjunctival block.

\section{Patients and methods}

Thirty eyes of 30 patients undergoing cataract surgery by phacoemulsification technique were studied prospectively. Patients with known diabetes, glaucoma, ocular hypertension (IOP above $24 \mathrm{~mm} \mathrm{Hg}$ ), and previous intraocular surgery were excluded. None of the patients selected suffered from myopia greater than -4 dioptres. After informed consent, patients were randomly allocated to have either peribulbar (with or without compression) or subconjunctival LA. In the peribulbar group, there were 20 patients, seven males and 13 females with a mean age of 78.0 years (range 58-90 years). Ten eyes of 10 patients received peribulbar LA and 10 minutes of compression with a Honan's balloon at $30 \mathrm{~mm} \mathrm{Hg}$ (group A). The other 10 patients received peribulbar LA alone (group B). In the subconjunctival group (group C), there were six males and four females with a mean age of 79.6 years (range 66-89 years).

LOCAL ANAESTHETIC TECHNIQUES

All eyes received topical amethocaine 1\% shortly before each measurement. The pupils of eyes receiving LA were dilated with cyclopentolate $1 \%$, phenylephrine $2.5 \%$, and flurbiprofen eye drops at 90, 60, and 30 minutes before the block.
PERIBULBAR GROUP (GROUPS A AND B)

Ten $\mathrm{ml}$ of an equal mixture of lignocaine $2 \%$ and bupivacaine $0.75 \%$ (plus 150 units hyaluronidase) were injected into the peribulbar space transconjunctivally, inferotemporally, and medially. Exactly the same technique was used for all eyes. All injections took under 1 


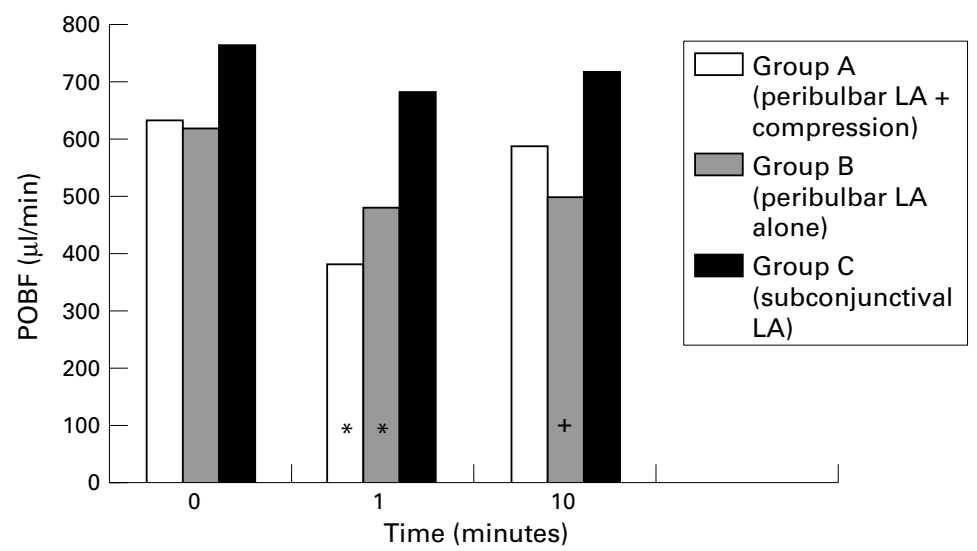

Figure 1 Median pulsatile ocular blood flow (POBF) before and after local anaesthesia. $\star$ Statistically significant drop $(p<0.01)$ in POBF + Statistically significant drop $(p<0.05)$ in POBF

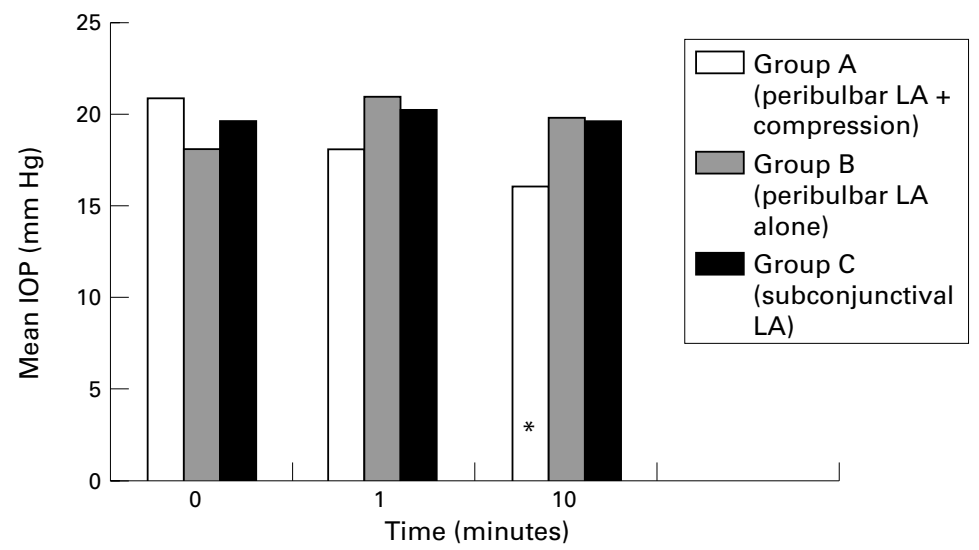

Figure 2 Mean IOP ( $m m$ Hg) before and after local anaesthesia. *Statistically significant drop in IOP after 10 minutes of compression $(p<0.05)$.

minute to perform. POBF and IOP were measured immediately before LA, 1 minute after LA, and 10 minutes after LA. In group A, final measurement was after 10 minutes' compression with a Honan's balloon at a pressure of $30 \mathrm{~mm} \mathrm{Hg}$.

SUBCONJUNCTIVAL GROUP (GROUP C)

A subconjunctival injection of an equal mixture of lignocaine $2 \%$ (with 1 in 200000 adrenaline) and bupivacaine $0.75 \%$ was used; $0.3-0.5 \mathrm{ml}$ was injected into the superior limbal conjunctiva and $0.5 \mathrm{ml}$ through the upper eyelid skin over the superior rectus (SR) muscle to facilitate insertion of a lid speculum. POBF and IOP were measured as in the peribulbar group.

All measurements were made by the same experienced operator with the patient in a supine position, using the ocular blood flow tonograph, a modified Langham pneumatonometer linked to an integral computer (OBF Labs, UK Ltd).

\section{STATISTICAL ANALYSIS}

Comparisons of IOP within groups were done using a paired $t$ test. Comparison of IOP among the three groups (peribulbar LA with and without compression and subconjunctival LA) were done using an unpaired $t$ test.

Pulsatile ocular blood flow has been shown not to have a normal Gaussian distribution ${ }^{5}$ and so non-parametric tests were used in analysing POBF changes. The Wilcoxon signed rank test was used to compare POBF within groups and the rank sum test for unpaired data used to compare POBF among the three groups.

\section{Results}

PULSATILE OCULAR BLOOD FLOW

Median pulsatile ocular blood flow before LA was $631.5 \mu \mathrm{l} / \mathrm{min}$ (range $219-1069 \mu \mathrm{l} / \mathrm{min}$ ) in group A, $618 \mu \mathrm{l} / \mathrm{min}$ (range $291-1346 \mu 1 / \mathrm{min}$ ) in group B and $762 \mu \mathrm{l} / \mathrm{min}$ (range 485-1790 $\mu 1 / \mathrm{min}$ ) in group C. There was no statistically significant difference $(p>0.05)$ in POBF in the three groups before LA was administered ( 0 minutes).

In group A, 1 minute after peribulbar LA, the median POBF decreased from 631.5 $\mu \mathrm{l} / \mathrm{min}$ to $379 \mu \mathrm{l} / \mathrm{min}$ and in group $B$ the decrease was from $618 \mu \mathrm{l} / \mathrm{min}$ to $480 \mu \mathrm{l} / \mathrm{min}$ (Fig 1). This reduction was statistically significant $(p<0.01)$ in both groups. After 10 minutes, POBF tended to return towards baseline levels but remained significantly lower in group B $(p<0.05)$ where compression was not applied. However, POBF was no longer significantly reduced in group A after 10 minutes of compression with a Honan's balloon $(p>0.05)$. In the subconjunctival group C (Fig 1), there was no significant change in POBF at any stage $(\mathrm{p}>0.05)$.

INTRAOCULAR PRESSURE

The baseline IOP in groups $\mathrm{A}, \mathrm{B}$, and $\mathrm{C}$ was 20.84 (SD 3.51) $\mathrm{mm} \mathrm{Hg}, 18.11$ (2.97) $\mathrm{mm} \mathrm{Hg}$, and 19.55 (3.68) $\mathrm{mm} \mathrm{Hg}$, respectively, with no statistically significant intergroup differences $(p>0.05)$. In group $A$, there was no change in IOP 1 minute after LA, but after 10 minutes of compression with a Honan's balloon, IOP decreased from a mean of $20.84(3.51) \mathrm{mm} \mathrm{Hg}$ to a mean of $16.02(5.66) \mathrm{mm} \mathrm{Hg}$. The fall at 10 minutes was a statistically significant $(\mathrm{p}<0.05)$ reduction in IOP. In the peribulbar group B (without compression) and the subconjunctival group $\mathrm{C}$, there was no significant change in IOP either before or after LA (Fig 2).

\section{Discussion}

Ultrasound (Doppler), pneumatonography, videoangiography, blue field entoptoscopy, laser velocimetry, and ophthalmodynamometry have been used to measure different components of ocular blood flow but these techniques are unable to measure optic nerve head circulation directly. ${ }^{6}$ The Heidelberg retinal flowmeter can measure optic nerve and retinal blood flow but only in small, specific areas. ${ }^{7}$ Pneumatonography used in the present study measures the pulsatile component of blood flow, a major component of total ocular blood flow and includes choroidal blood flow. ${ }^{8}$ To measure POBF, a column of air is directed towards a flexible membrane at the tonography head which is in contact with the corneal surface. The stream of gas exerts pressure on the corneal surface against an opposing force produced by the IOP. The IOP wave profile varies with each heart beat. The variation in 
IOP is called the pulse amplitude from which POBF can be calculated automatically by a computer. ${ }^{910}$ The technique of pneumatonometry is easy to perform and reproducible.

Choroidal circulation accounts for about $90 \%$ of total ocular circulation and is under autonomic control via $\alpha$ and $\beta$ receptors. ${ }^{11}$ Since optic nerve head circulation almost entirely originates from the choroidal circulation, it is not illogical to assume that any fluctuation within the choroidal circulation could indirectly affect optic nerve head circulation. ${ }^{12}$ Although this cannot be taken for granted, there are no better techniques available to measure optic nerve head circulation. Furthermore, assessment of changes in choroidal blood flow provided is valuable in that it can highlight potential adverse effects of compromised circulation on the outer layers of the retina. ${ }^{813}$

When patients assume a supine position there is an increase in IOP and decreased $\mathrm{POBF}^{14}$ and the reduction is greater in those with glaucoma. ${ }^{15}$ In the present study, glaucoma patients were excluded and all measurements were made with patients in a supine position. Measurements of IOP and POBF were made after the administration of topical amethocaine in all eyes (study and control) and after instillation of cyclopentolate, phenylephrine, and flurbiprofen in the eyes to be blocked. The authors were aware of the effects of these drugs on ocular haemodynamics. Cyclopentolate, an anticholinergic, and phenylephrine, an $\alpha$ agonist, have vasoconstrictor properties. Amethocaine is an ester based local anaesthetic with mild vasodilator properties.

It is assumed that an increase in IOP causes a reduction in ocular blood flow probably by causing a reduction in perfusion pressure and by obstruction of venous drainage, although this simplistic hypothesis does not allow for autoregulation. An injection of a high volume of anaesthetic agent into the orbit may therefore reduce ocular blood flow by increasing IOP at least in the short term. Oculocompression can have a beneficial effect on ocular circulation by decreasing IOP and increasing perfusion pressure ${ }^{16}$ and this was employed in group A. The present study compared peribulbar LA with and without balloon compression as well as comparing peribulbar and subconjunctival LA. A retrobulbar group was not enrolled because of the similarities with peribulbar LA. It has been shown that both retrobulbar and peribulbar techniques increase IOP in a similar fashion. ${ }^{18}$ Furthermore, retrobulbar LA has virtually been abandoned in favour of peribulbar LA in patients requiring this degree of anaesthesia. Oculocompression with a Honan's balloon is used in order to avoid the potential rise in IOP following peribulbar LA. ${ }^{18}$ Although expected, there was no increase in IOP recorded at 1 minute in the present study. However, after 10 minutes of compression with a Honan's balloon, IOP fell by a significant degree.

The present study showed that peribulbar LA causes an immediate, statistically significant fall in POBF. The fall in POBF may be due to an inherent property of local anaesthetics which impairs blood flow. Meyer et $a l^{19}$ showed that LAs like bupivacaine can impair nitric oxide mediated relaxation in porcine ciliary arteries, thereby decreasing ocular blood flow. In a similar study by Findl et $a l^{20}$ reductions in pulsatile choroidal blood flow (by laser interferometry) and reductions in retinal blood flow velocities (by Doppler sonography) were measured at 1 and 5 minutes after peribulbar LA. They also suggested a drug induced vasoconstriction as the cause. They did not, however, investigate the role of ocular compression nor whether this reduction in blood flow continued beyond 5 minutes.

Following peribulbar LA, POBF gradually returned towards baseline levels but remained significantly reduced at 10 minutes without balloon compression. The reduction in IOP with compression may improve POBF by improving perfusion pressure. Although balloon compression helped POBF recover to near baseline by 10 minutes, the delay is possibly still long enough to enhance ocular ischaemia, especially with the patient in a supine position, possibly on hypertensive treatment. and particularly when there is pre-existing compromised ocular circulation.

The findings may have clinical implications when intraocular surgery is contemplated in patients with compromised ocular circulation where subconjunctival or topical anaesthesia is recommended wherever possible.

The authors thank $\mathrm{Mr} \mathrm{T}$ Alaghebandian for his help and support.

1 O'Donohue E, Batterby M, Lavy T. Effect on intraocular pressure of local anaesthesia in eyes undergoing intraocular surgery. Br F Ophthalmol 1994;78:605-7.

2 Bowman R, Liu C, Sarkies N. Intraocular pressure changes after peribulbar injections with and without ocular compression. Br f Ophthalmol 1996;80:394-7.

3 Langham ME, Farrell MA, O'Brien V, et al. Blood flow in the human eye. Acta Ophthalmol (Copenh) 1989;67(suppl 191):9-12.

4 Henkind P, Hansen RJ, Szaky J. Ocular circulation. In: Duane TD, Jaeger EA, eds. Biomedical foundations of ophthalmology II. Philadelphia: Harper and Row, 1986:1-54

5 Massey AD, O'Brien C, Aspinall P, et al. Pulsatile ocular Massey $\mathrm{AD}$, O'Brien C, Aspinal P, et al. Pulsatile ocular
blood flow: population study of normals. Invest Ophthalmol Vis Sci 1996;37:S31.

6 Williamson TH What is the use of ocular blood flow measurement? Br f Ophthalmol 1994;78:326.

7 Kagemann L, Harris A, Chung HS, et al. Heidelberg retinal flowmetry: factors affecting blood flow measurement . $\mathrm{Br} \mathcal{F}$ Ophthalmol 1998;82:131-6.

8 Langham ME, Farrell RA, O'Brien V, et al. Non-invasive measurements of POBF in the human eye. In: Lambrou $\mathrm{GN}$, Greve EL, eds. Ocular blood flow in glaucoma. Amsterdam: Kugler and Ghedini, 1989:93-9.

9 Silver DM, Farrell RA. Validity of pulsatile ocular blood flow measurements. Surv Ophthalmol 1994;38(suppl):72-80.

10 Spry P. Tonometry with a difference. Optician 1996;No 5537,211:24-6.

11 Kiel JW, Lovell MO. Adrenergic modulation of choroidal blood flow in rabbit. Invest Ophthalmol Vis Sci 1997;37: 673-9.

12 Bosom ME, Lusky M, Weinreb RN. The effect of levobunalol on pulsatile ocular blood flow. Am f Ophthalmol 1992;114:280-6.

13 Hitchings R. The ocular pulse (Editorial). Br f Ophthalmol 1991;75:65

14 Trew DR, Smith SE. Postural studies in pulsatile ocular blood flow: I Ocular hypertension and normotension. $\mathrm{Br} F$ Ophthalmol 1991;75:66-70.

15 Trew DR, Smith SE. Postural studies in pulsatile ocular blood flow: II Chronic open angle glaucoma. Br f Ophthalmol 1991;75:71-5.

16 Hessemer V, Heinrich A, Jacobi KW. Intraocular pressure and ocular haemodynamics following oculocompression with and without added retrobulbar anaesthesia. Fortschr Ophthalmol 1989;86:762-7.

17 Hessemer V. Anaesthesia effects on ocular circulation. Fortschr Ophthalmol 1991;88:577-87.

18 Meyer D, Hamilton RC, Loken RG, et al. Effect of combined peribulbar and retrobulbar injection of large volumes of anaesthetic agents on intraocular pressure. Can $\mathcal{F}$ Ophthalmol 1992;27:230-2. 
19 Meyer P, Flammer J, Luscher TF. Local anaesthetic drugs reduce endothelium-dependent relocations of porcine cilireduce endothelium-dependent relaxations of porcine
ary arteries. Invest Ophthalmol Vis Sci 1993;34:2730-6.
20 Findl O, Dallinger S, Menapace R, et al. Effects of peribulbar anaesthesia on ocular blood flow in patients undergoing cataract surgery. Am f Ophthalmol 1999;127:645-9.

\section{Contributors please note:}

Communications from all countries except the UK and Republic of Ireland should be sent to Professor C Hoyt, Editor, British fournal of Ophthalmology, University of California, Department of Ophthalmology, 10 Kirkham Street, K 301, San Francisco, CA 94143-0730, USA (tel: 001415 502-6871; fax: 001415 514-1521).

Manuscripts from the UK and the Republic of Ireland should be sent to Professor Andrew Dick, UK Editor, British fournal of Ophthalmology, Division of Ophthalmology, University of Bristol, Lower Maudlin Street, Bristol BS1 2LX (tel: +44 (0) 0117 929-4496; fax: +44 (0) 117 929-4607). 